\title{
Analysis and study of the influence of the geometrical parameters of mini unmanned quad-rotor helicopters to optimise energy saving
}

\author{
I. Penkov ${ }^{1}$ and D. Aleksandrov ${ }^{2}$ \\ ${ }^{1}$ School of Engineering, Department of Mechanical and Industrial Engineering, \\ Tallinn University of Technology, Estonia \\ E-mail: igor.penkov@ttu.ee, Phone: +3725169922 \\ ${ }^{2}$ PLM Group, Estonia
}

\begin{abstract}
The article discusses lift force generated by mini UAVs (Unmanned Aerial Vehicles). CFD (Computational Fluid Dynamics) simulations were made on the base of a 3D scanned propeller model. Influence of some geometrical parameters of propeller (like velocity or pitch) and quadcopter (like gap) on lifting force was considered. Different propeller pitches were used and pitch influence on propeller lift force was analysed. Normally, lifting force will increase with the increasing of propeller pitch but for different rotation velocities, this increasing is different and in all cases, it can be approximated by a linear relationship. To obtain dependency functions, an equation for calculation of lift force given took into account the correction coefficients. This equation gave reliable results at pitch values equal to $0.3-0.7$ of the propeller diameter and at rotation velocities of $2000 \mathrm{~min}^{-1}-8000 \mathrm{~min}^{-1}$.

Lift force dependency from distance between rotors was also considered. Simulations and experiments showed that the lifting force of a quadcopter increased about $15 \%$ on gap distances from $5 \mathrm{~mm}$ to $35 \mathrm{~mm}$. From a distance of $70 \mathrm{~mm}$, the lifting force will decrease about $2 \%$ and then will stabilise. At increasing of distance between propellers from $5 \mathrm{~mm}$ until $25 \mathrm{~mm}$, the power consumption decreased $8 \%-10 \%$ and after the gap distance equal to $40 \mathrm{~mm}$, it will be stable and minimal. It can be asserted that quadcopters have different optimal distances between the propellers at different rotation speeds to generate the same force. Equations for calculation of optimal gap distances for different multicopters were derived and calculation results are presented in graphs and tables.
\end{abstract}

Keywords: UAV, CFD Simulation, Quadcopter, Lift Force, Rotor, Gap, Energy Saving.

\section{INTRODUCTION}

In the last decades, many autonomous and teleoperated vehicles in the applications of robotics have been developed, including wheeled or tracked and legged vehicles. However, in many cases, ground vehicles have significant inherent limitations to access desired locations due to the characteristics of the terrain and the presence of obstacles. In these cases, aerial vehicles are the natural way to approach the objective to obtain information or even to perform necessary actions such as the deployment of instrumentation [1]. Unmanned aerial vehicles are widely used in various civil $[2,3]$ and military [4] applications, for example for traffic monitoring [5, 6], navigation $[7,8]$ and aerial mapping. UAVs are used for agriculture $[9,10]$ needs, press, television, 
cinematography $[11,12]$, marine application, pollution detection and other fields. UAVs are capable of carrying out work under conditions where the surrounding environment is dangerous or not accessible to humans. They can carry out many military applications such as border patrol monitoring [13] and drug smugglers detection, uninhabited combat aerial vehicles and radar saturation roles. UAVs have generated great interest in industrial and academic areas [14-16] due to small size [17-19], unique flight capacities [20-22], outstanding maneuverability and low cost. A lot of researches related to stability and controllability are being conducted [23-26]. Mathematical calculation methods, basis of screw theory [27], analysis of joining between components [28] and optimisation of kinematic parameters [29] are also usually used for the development of UAVs.

One very important part in analysing UAVs is rotors energy saving and increasing the system capacity. Many different parameters like mass, design, environment and other influence on energy consumption [30-32]. The work by [33] tried to save system energy by chattering reduction during mini UAV control. Work by [34, 35] considered thrust optimisation in rotors with two and three propellers. The main purposes of this research are to consider the influence of rotor pitch and gap between rotors on lift force and power consumption of a quadcopter. Analysis will be done with the help of CFD simulations and laboratory tests. Normally, the increase in propeller pitch causes increase in lifting force magnitude but it is interesting to know the influence of different velocities. Relationship between lifting force produced by rotors and quadcopter mass gives information about system efficiency and it is beneficial to know the optimal design parameters in a quadcopter.

\section{METHODS AND MATERIALS}

\section{CFD Modelling}

Lifting force generated by propeller was carried out owing to an air flow created near the propeller and directed down (Figure 1). The simulating models (Figure 2 (a)) were created on the base of real propellers (DF-1050CR from Draganfly Innovations, airfoil type similar to NACA6409) with diameter of $254 \mathrm{~mm}$ and pitch of $127 \mathrm{~mm}$ as well as a propeller with diameter of $203.2 \mathrm{~mm}$ and pitch of $101.6 \mathrm{~mm}$, scanned with the help of a 3D scanner. The scanned models were imported in SolidWorks Flow Simulation as point cloud data [36]. Then, working models were created and lifting force of propellers was determined at different rotation speeds.

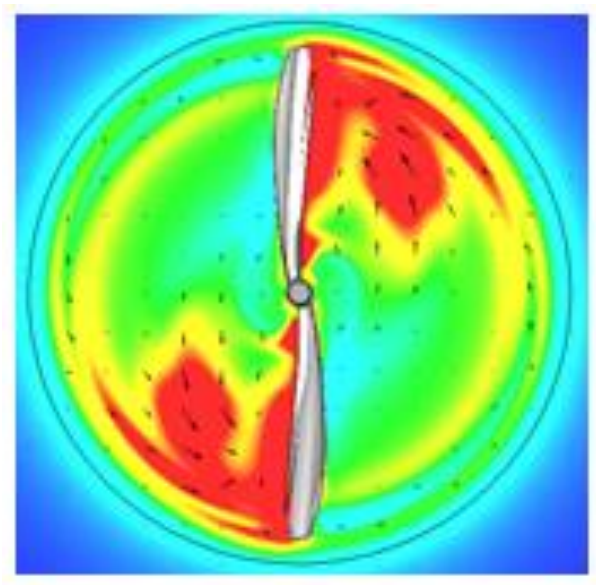

Figure 1. Air stream near the propeller. 


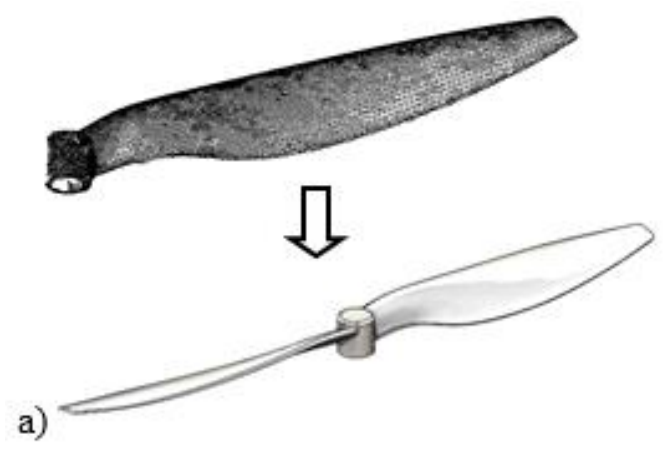

b)

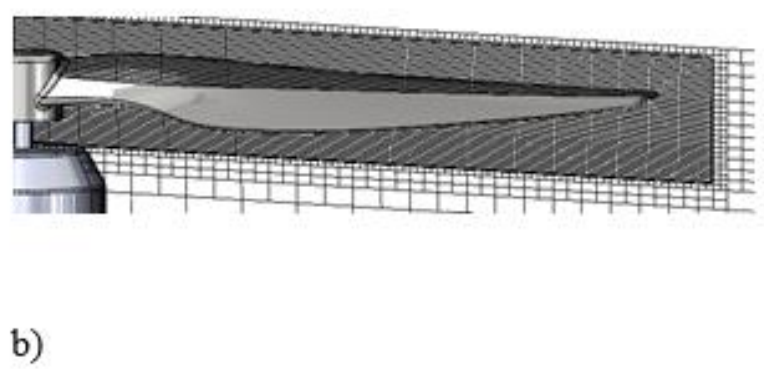

Figure 2. Models for CFD simulation for $254 \mathrm{~mm}$ propeller (a) 3D scanned data; (b) FVM mesh.

CFD simulations were made using external computational domain with a local rotating region. The environment was filled by air with a density of $1.2 \mathrm{~kg} / \mathrm{m}^{3}$. Normal environmental conditions with pressure $101325 \mathrm{~Pa}$ and temperature $293.2 \mathrm{~K}$ were used. Temperature change effects were not taken into account. Meshing was done by manual mesh control using planes and mesh refinement around the propeller's curved surfaces (Figure 2(b)). Mesh refinement reduced the number of partial cells (cells that were partly solid and partly fluid). All the simulations were made in steady-state mode until convergence of the lifting force was less than $0.02 \mathrm{~N}$ (around $0.3 \%$ of the whole amount of the lifting force). In Figure 3, streamlines and vectors show air velocity and flow direction. Colours show pressure difference near the rotating propeller. Pressure difference between the top and bottom surfaces of the propeller generated the lifting force. Edges of the rotating propeller created a turbulent area, where the flow went upwards and this stream partially compensated lower pressure region on top and the lifting force decreased.
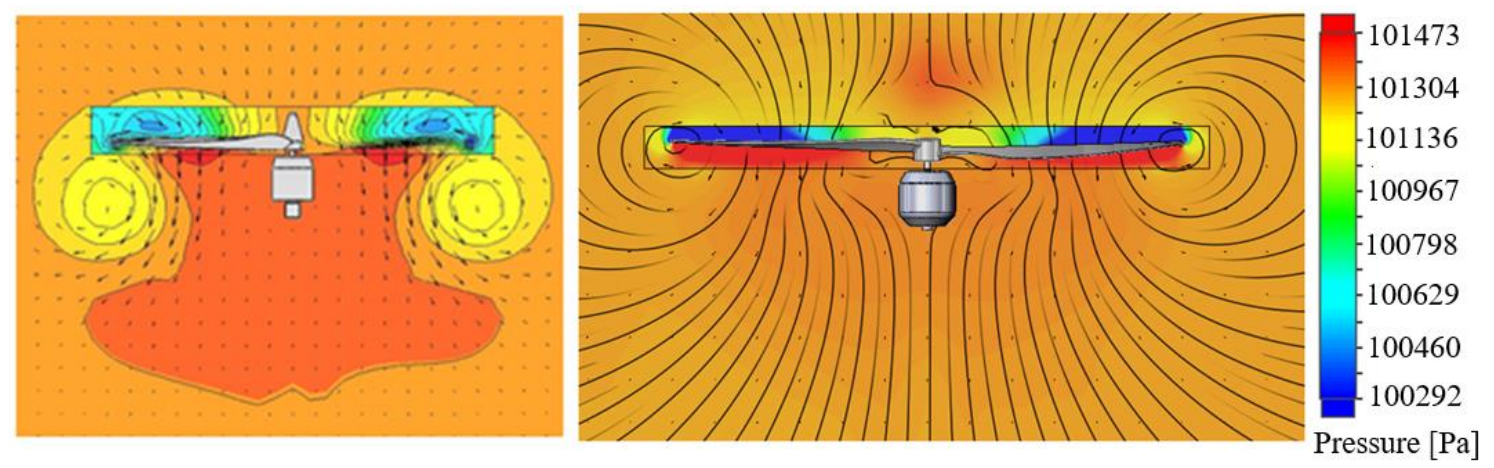

Figure 3. Pressure distribution near the propeller.

\section{Experiments Study}

In the experiments, a brushless motor Robbie 2827-34 with propellers $254 \times 127 \mathrm{~mm}$ and 203.2 x $101.6 \mathrm{~mm}$ was used. For motor control, a brushless motor controller (ESC) BLCTRL 1.2 from the Mikrokopter Company was used, operated through RS232 port directly from PC (using UM232R USB Serial UART Development Module by FTDI Company). For control, freeware software KopterTool V1_78B from a brushless motor controller developer was used. To determine motor power consumption, a bypass resistor was used. Experiments were made by help of a testing device shown in Figure 4. Heavy 
base was fixed with a strain gauge sensor PS-08844244 to a motor with a propeller fixed to it. Propeller rotation speed was measured with an optical laser tachometer Omron CT6. Altogether, ten values of rotational speed were measured for each propeller size.

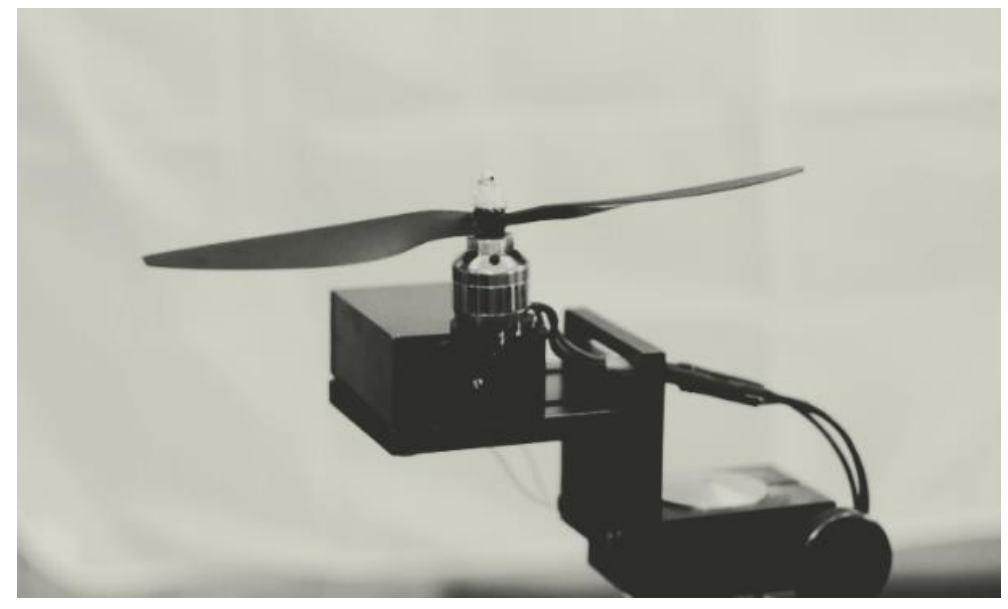

Figure 4. Testing device for the determination of propeller lifting force.

\section{RESULTS AND DISCUSSION}

Experiment results (Figure 5) were approximated using non-linear regression analysis software [37]. Lifting force dependency on the propeller rotation speed can be expressed as follows:

$$
F=0.486 \cdot 10^{-6} \cdot n^{1.882}
$$

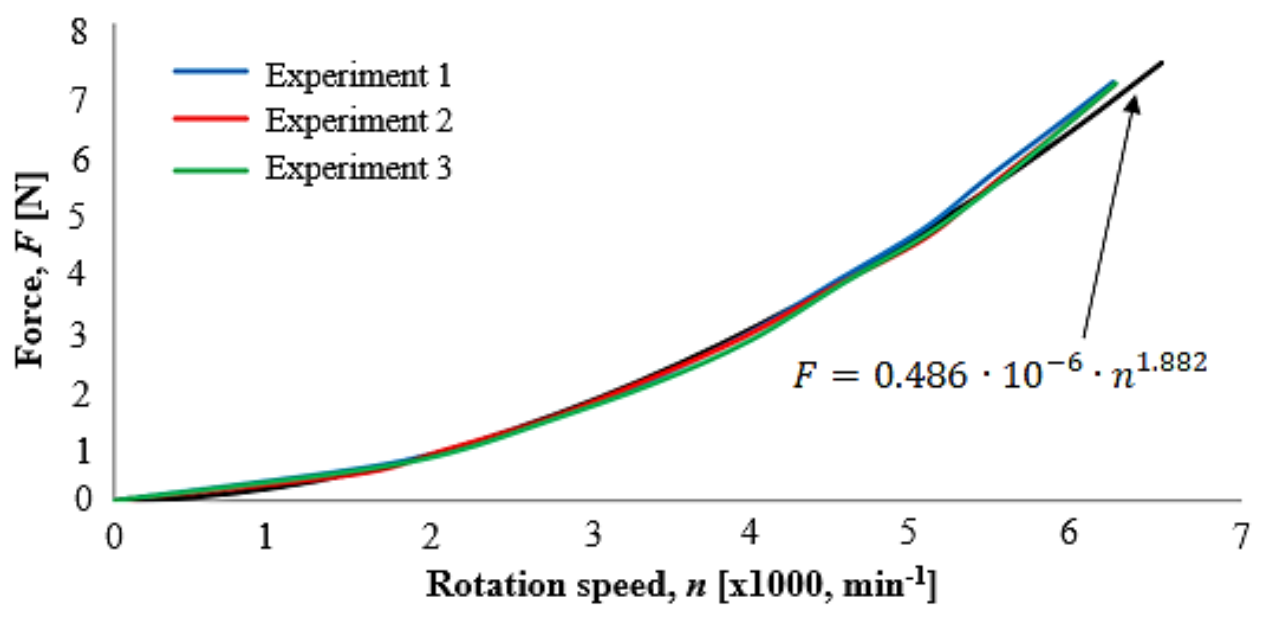

Figure 5. Data of three experiments and approximated result of the dependency of the lifting force on the rotation speed ( $254 \mathrm{~mm}$ propeller).

\section{Power Consumption Measurement}

Power consumption was measured by a bypass resistor SH-15-30A-75 with voltage 75 $\mathrm{mV}$ and current $15 / 30 \mathrm{~A}$. Results of the experiments with a $254 \mathrm{~mm}$ propeller are shown in Figure 6. Each step on the graph corresponds to a certain propeller rotation speed and energy consumption in hovering was stable. Figure 7 shows the dependency of the lifting force on motor power consumption. Motor power consumption behaviour can be 
described as linear (Figure 7), at least at working angular velocities (when rotor creates $1.0-7.0 \mathrm{~N}$ of lifting force). In the considered case, the influence of rotation speed on power consumption was also close to linear. Usually, the dependency of rotation speed on the motor energy consumption has a parabolic form, where the power consumption is proportionally lower at lower velocities than at higher.

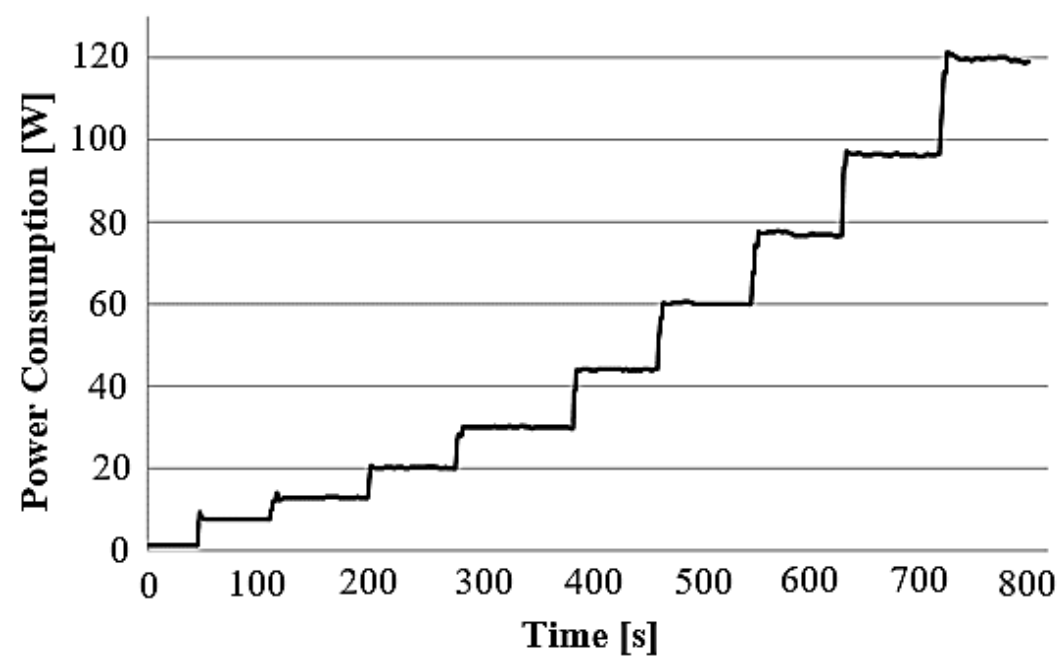

Figure 6. Motor power consumption in time.

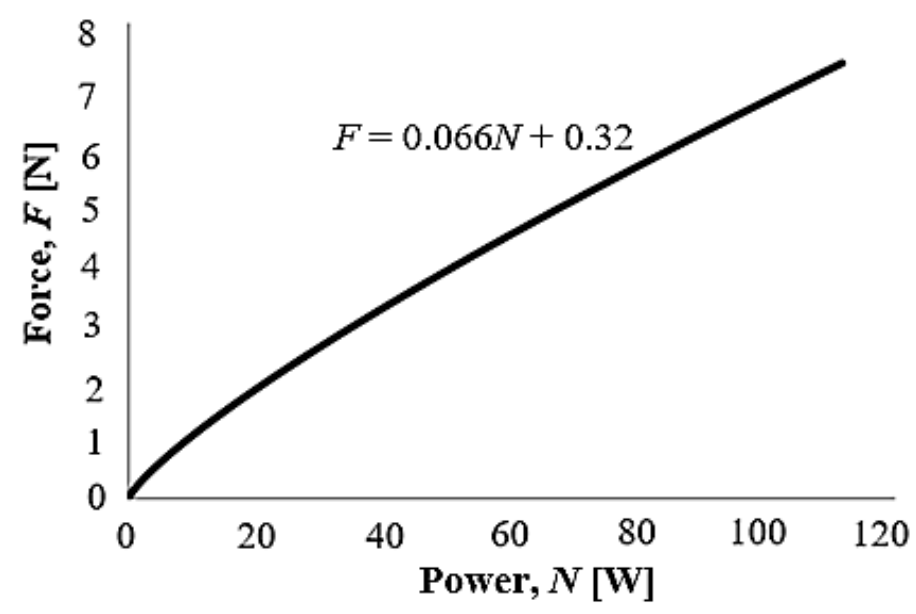

Figure 7. Dependency of the lifting force on motor power consumption.

\section{Comparison of Simulation and Experiment Results}

Figure 8 illustrates force dependency on the propeller rotation speed (Figure8 (a) compares forces produced by $254 \times 127 \mathrm{~mm}$ propeller and Figure 8(b) shows the same data for 203.2 x $101.6 \mathrm{~mm}$ propeller). Experiment force graphs were made on the base of the tests data and CFD force graphs by simulations. Both methods gave approximately similar results. Maximum deflection between simulations and experiment data was about 3\%. This means that the current CFD software can be used for similar analysis and comparison of propellers with different parameters. 

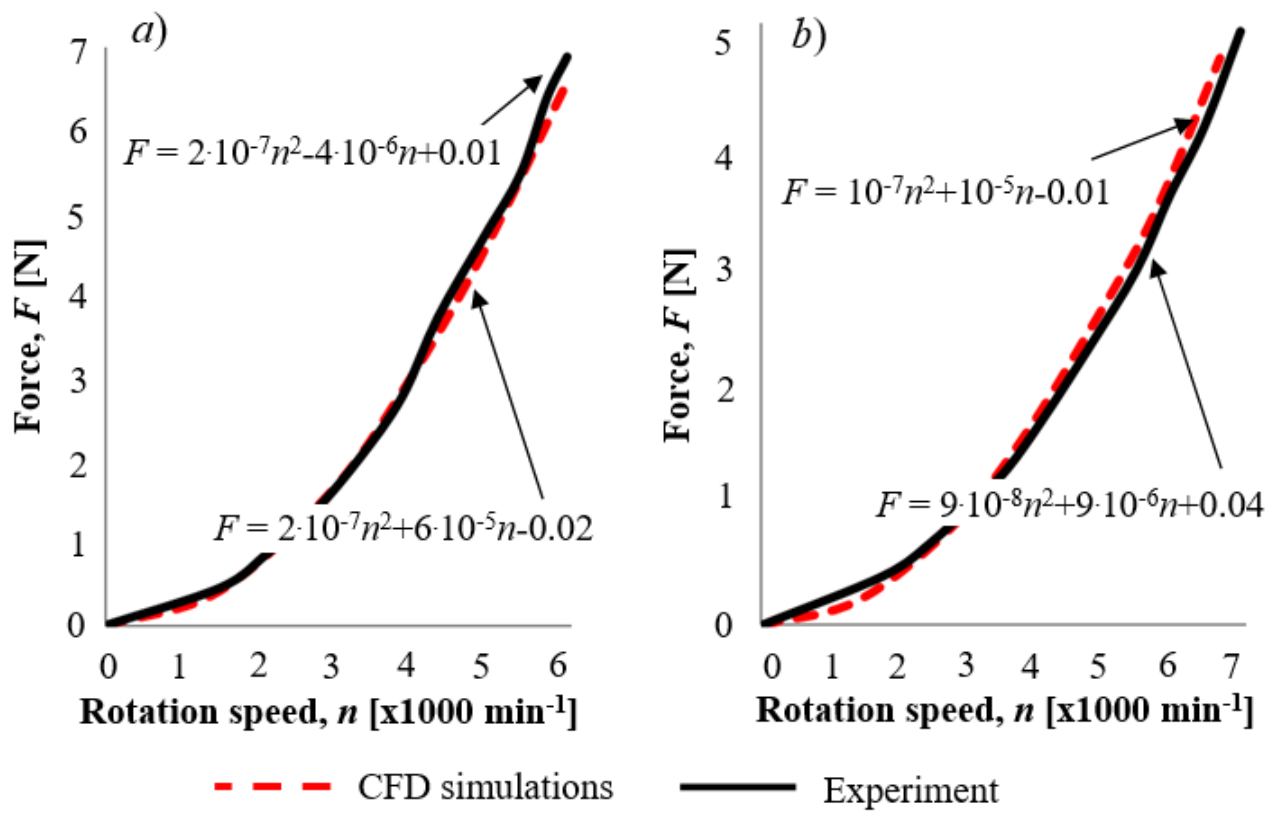

Figure 8. Dependency of the lifting force on the rotation speed; (a) $254 \times 127 \mathrm{~mm}$ propeller; (b) $203.2 \times 101.6 \mathrm{~mm}$ propeller.

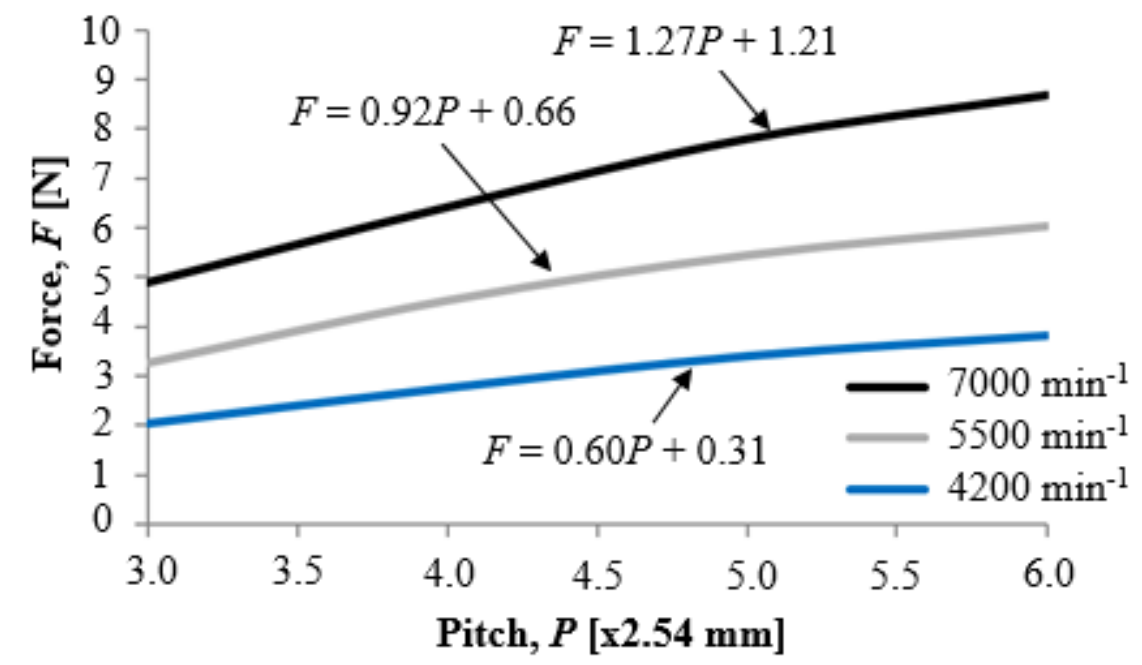

Figure 9. Dependency of the lifting force on pitch for $254 \mathrm{~mm}$ propeller.

\section{Propeller Pitch Influence on Lift Force}

Propellers with the same diameter can have different pitches. Let us consider pitch influence on lift load value. Theoretically, the higher the pitch, the higher the lifting force that can be produced but in reality, an increase in pitch size will generate an additional load on the motor and its combination with the propeller can be ineffective. Usually, pitch changes in the range of $0.7-1.3$ radius of the propeller. Median value of pitch is half of a propeller's diameter. All the other calculations have this ratio between pitch and propeller diameter. Let us consider the influence of pitch on the lifting force. Simulations compare propellers with the same diameter and rotating velocity but with different pitches. Figure 9 shows the dependence of the lifting force on the propeller pitch for different rotation speeds. All these functions can be described by linear laws with a high coefficient of determination. Simulations were made only on "working" rotation speeds 
that can be used in reality $\left(2000-8000 \mathrm{~min}^{-1}\right)$. Common dependency between propeller pitch and lifting force can be found by considering all three lines (Figure 9) together. Change of lift force can be presented by correction values that for example for $254 \mathrm{~mm}$ (10 inch) propeller can be expressed by Eq. 2. The equation takes into account both positive and negative values, depending on the pitch more or less than $127 \mathrm{~mm}$ (half of the propeller diameter). Adding parameter $F_{C-10}$ to the value of lifting force (Eq. 1) can show lifting forces generated by propeller with pitches different from half of the propeller diameter. This equation is not related to the rotation speed (and therefore unrelated to the exact lifting force) and can be used only for defined velocities.

$$
F_{C-10}=(P-127) \cdot 0.037
$$

Simulations for the determination of the dependency of the lifting force on pitch were also made for $203.2 \mathrm{~mm}$ and $304.8 \mathrm{~mm}$ rpropellers ( 8 inch and $12 \mathrm{inch}$ ). Those dependencies were also linear and can be described by Eq. 3 (similar to Eq. 2).

$$
F_{C-8}=(P-101.6) \cdot 0.018, F_{C-12}=(P-152.4) \cdot 0.051 .
$$

Combination of Eq. 2 and 3 will result in the overall correction coefficient $F_{C}$ (Eq. 4). Using the parameter $F_{C}$, it is possible to forecast how the lifting force will change if the propeller pitch will be different from half of the diameter. This formula gives reliable results at pitch values equal to $0.3-0.7$ of the propeller diameter and at rotation velocities $2000-8000 \mathrm{~min}^{-1}$.

$$
F_{C}=\left(P-\frac{D}{2}\right) \cdot\left(3.27 \cdot 10^{-4} D-4.72 \cdot 10^{-2}\right)
$$

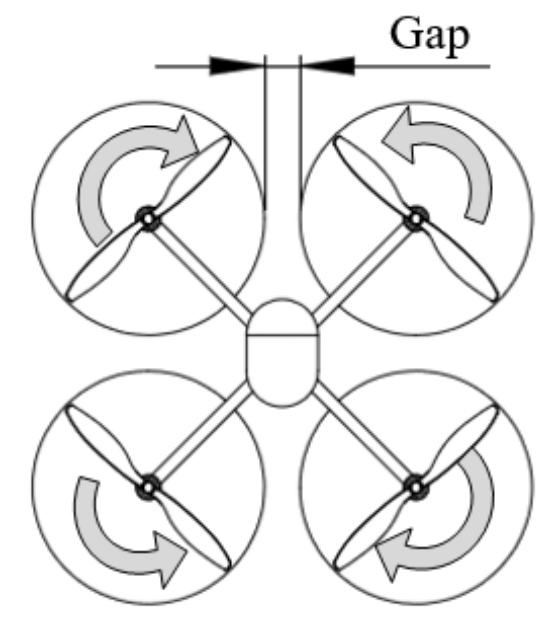

Figure 10. Simplified model of a quadrotor helicopter for CFD simulation.

\section{Optimal Gap Between Propellers}

\section{Influence of Distance between the Propellers on the Lifting Force}

The laminar and turbulent flows were created near the rotating propeller (Figures 1 and 3 ). When multicopter propellers were very close to each other, flows from them affected neighbouring propellers and their motor power consumption. With increasing distance between the propellers, the mass and dimensions of the helicopter increased and it is 
necessary to know an optimal gap distance between the propellers. In this case, the helicopter mass will be at minimum and propellers will generate a maximum lifting force - influence of border effect was minimal. To determine optimal distances, lifting forces of four-rotor flying platforms (mini UAV) with different distances between propellers were analysed. The air out-flows from the propellers were simulated and the lifting force was determined with CFD software. Figure 10 shows simplified model of a quadrotor helicopter for CFD simulation. Helicopters with different distances between the propellers at different angular velocities were compared. To compare the obtained results with real conditions, a series of experiments were done.

\section{Simulations}

Simulations for lifting force determination and gap distance optimisation were made on the base of a simplified quadrotor helicopter model with $254 \mathrm{~mm}$ propellers. Separate simulations for four different rotation speeds $1500 \mathrm{~min}^{-1}, 3000 \mathrm{~min}^{-1}, 4000 \mathrm{~min}^{-1}$ and 5000 $\mathrm{min}^{-1}$ were done [35]. For each rotation speed, the distance range between the propellers changed from $5 \mathrm{~mm}$ to $140 \mathrm{~mm}$ (Figure 11). Environmental conditions used were the same as before: air density was $1.2 \mathrm{~kg} / \mathrm{m}^{3}$, pressure $101325 \mathrm{~Pa}$ and temperature $293.2 \mathrm{~K}$. Results of the simulations showed that the lifting force produced by one propeller in quadrotor increased on distances from $5 \mathrm{~mm}$ to $35 \mathrm{~mm}$ (Figure 11) by about $15 \%$. From a distance of $70 \mathrm{~mm}$, the lifting force will decrease by about $2 \%$ and then will stabilise. This magnitude of lifting force was equal to the lifting force produced by one separately working propeller.

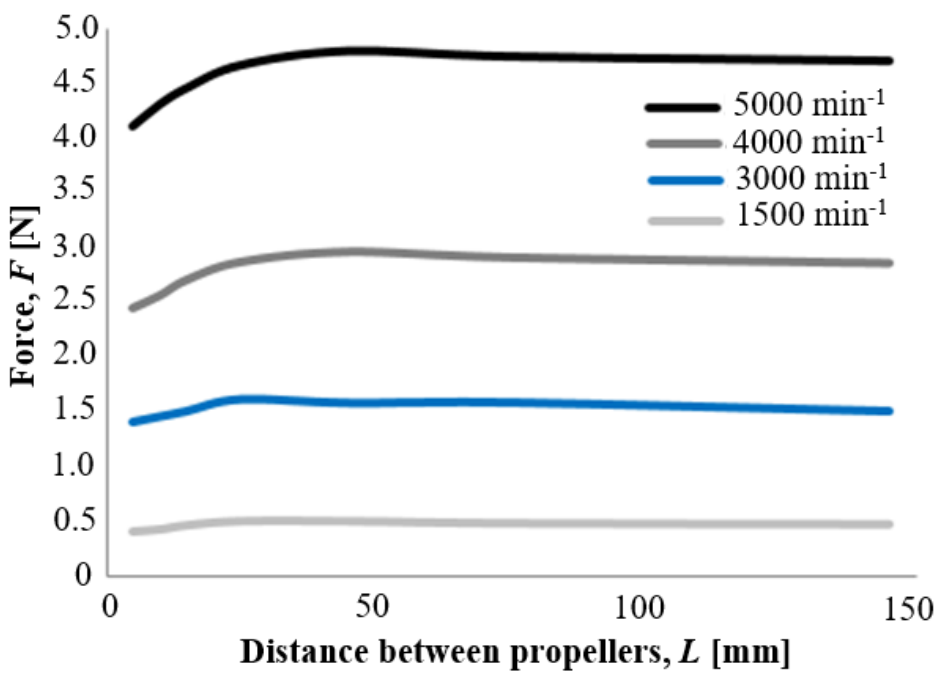

Figure 11. Dependency of the lifting force on the distance between the propellers.

Figure 12(a) shows airflow velocities and their directions of a quadrotor helicopter (front and top views) with $10 \mathrm{~mm}$ distance between the propellers. Velocity range was 0 $-13 \mathrm{~m} / \mathrm{s}$, darker areas near the propeller showed higher velocities. Small turbulent areas appeared near the propeller edge where air flow was twisting upwards. There was a space between the propellers where airflows were running into each other and the resulting flow moved upwards. This stream partially compensated the lifting force. Figure 12(b) illustrates airflow velocities and their directions when the distance between the propellers was $140 \mathrm{~mm}$. At this distance, the influence of airflows from the propellers was insufficient. Each propeller can be considered as separately working and total lifting force 
produced by quadcopter can be found as the sum of lifting forces produced by four propellers.
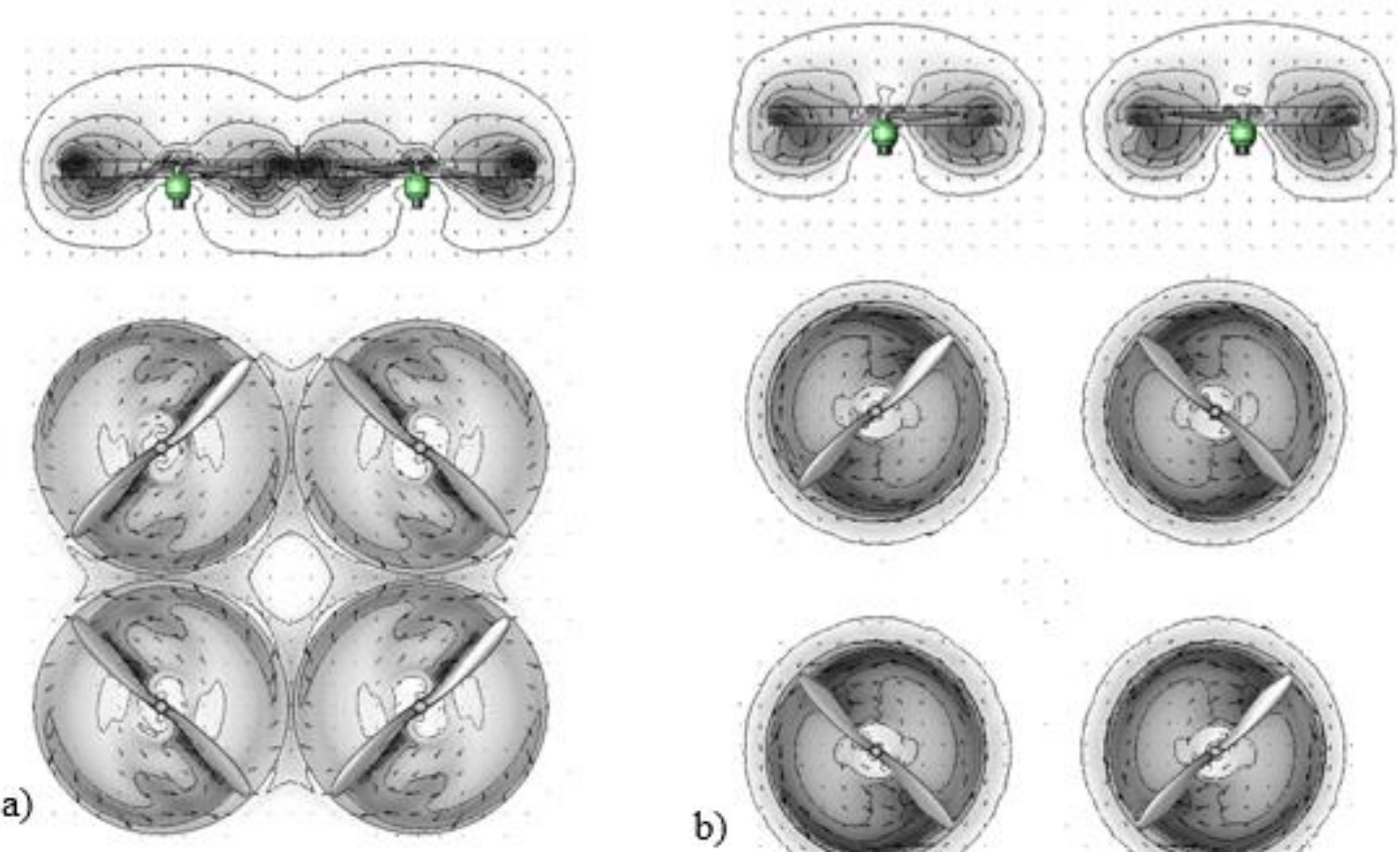

b)
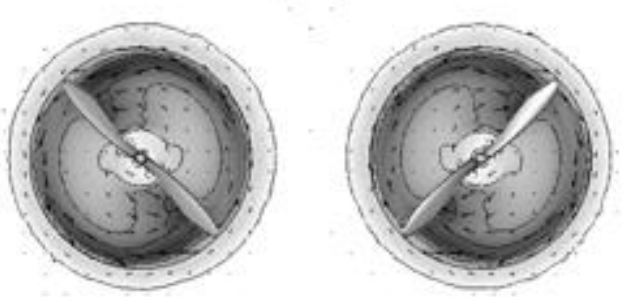

Figure 12. Air velocity distribution near the propellers.

a) distance between propellers is $10 \mathrm{~mm}$, and b) distance between propellers is $140 \mathrm{~mm}$

\section{Experiments Details}

A testing device was designed for experiments that allowed imitating a quadcopter with changing distance between the propellers. One of the four propellers was fixed on the force measurement device and the distance between propellers changed with steps of 10 $\mathrm{mm}$.

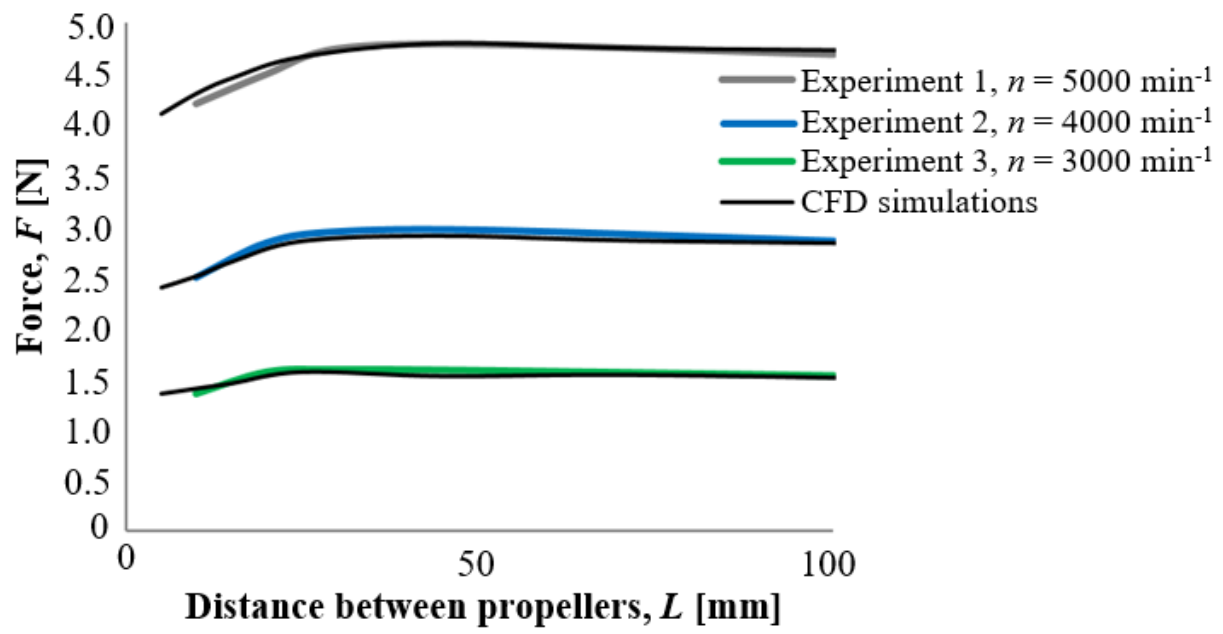

Figure 13. Dependency of the lifting force on the distance between the propellers. Comparison of experiment results with the CFD simulations. 
Figure 13 illustrates the dependency of the lifting force on the distance between the propellers for different rotor angular velocities. Both experiments and CFD simulations gave approximately similar results (maximum deviation is about 3\%). From Fig. 13, it can be seen that at the same angular velocity, the propeller can produce different lifting forces on different distances between the propellers. For example, at the angular velocity of $5000 \mathrm{~min}^{-1}$ a propeller produced $14.82 \%$ higher lifting force at distance between rotors equal to $40 \mathrm{~mm}$ than at the distance equal to $10 \mathrm{~mm}$. By increasing the distance between propellers from $5 \mathrm{~mm}$ until $25 \mathrm{~mm}$, the power consumption decreased $8 \%$ - 10\% and after the gap distance equal to $40 \mathrm{~mm}$ it will be stable and minimal. Figure 14 shows the dependency of motor power consumption on the distance between the propellers for different lifting forces produced by the rotor. Difference between optimal and the highest power consumption was $9.67 \%$ (without taking into account the increasing of quadcopter mass) while the propeller created a lifting force of $5 \mathrm{~N}$.

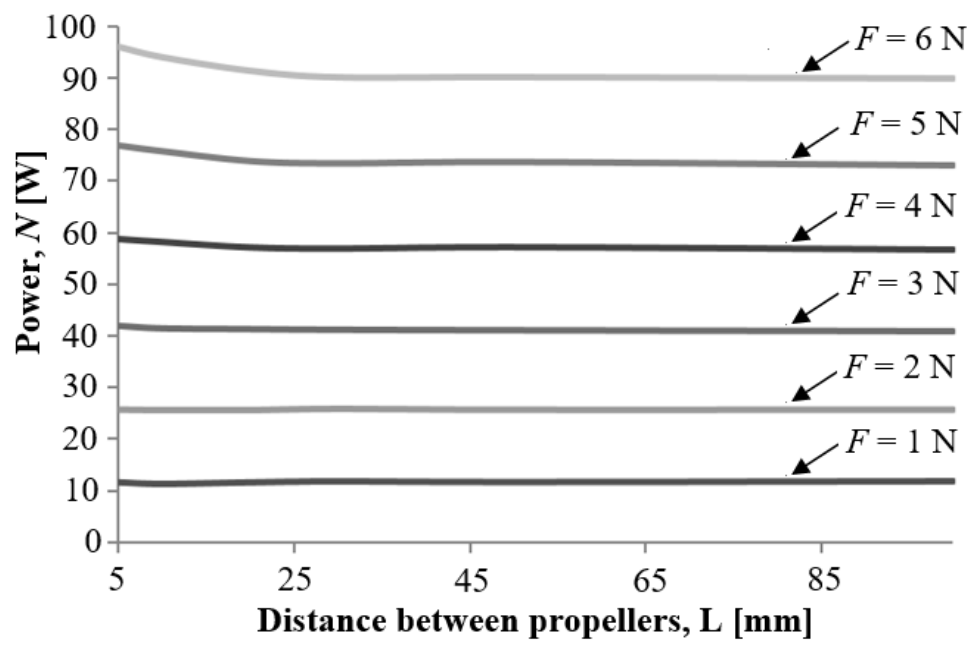

Figure 14. Dependency of motor power consumption on the distance between the propellers.

\section{Optimal Gap Distance Determination}

Optimal gap distance between the propellers is the distance when the propellers generate a maximum lifting force - air flows affect each other minimally. This distance should be considered in the hovering of a quadcopter. Helicopter mass is usually known and this fact allows easy-to-determine necessary lifting force produced by each propeller. To determine an optimal distance between propellers, it is necessary to know the energy quantity for producing a definite amount of lifting force. Since it is impossible to determine the real energy consumption by CFD software, propeller angular velocity was used as a compared parameter. To convert data, nonlinear regression analysis was made using Microsoft Excel Analysis ToolPack. Results are shown in Figure 15. Presented here are the angular velocities necessary for generating a definite amount of lifting force on a definite distance between the propellers. For example, to produce a lifting force equal to five newtons, the propeller needs to have the rotation velocity of $5698 \mathrm{~min}^{-1}$ at distance between propellers equal to $5 \mathrm{~mm}$ and a distance of $41 \mathrm{~mm}$, this velocity should be only $5319 \mathrm{~min}^{-1}$. For a precise determination of the optimal distance, the mass of the aerial vehicle had to be taken into account. Hereinafter was assumed that the mass per length of the UAV girder was equal to $0.25 \mathrm{~g} / \mathrm{mm}$. Thus, at the increasing of the distance between the rotors, the mass of the quadcopter also increased and a bigger lifting force was 
necessary for holding an aerial vehicle immovable in air. Figure 16 shows the dependency of the propeller angular velocity on the distance between the propellers for generating 5 $\mathrm{N}$ of lifting force. In this case, the optimal distance was equal to $41 \mathrm{~mm}$.

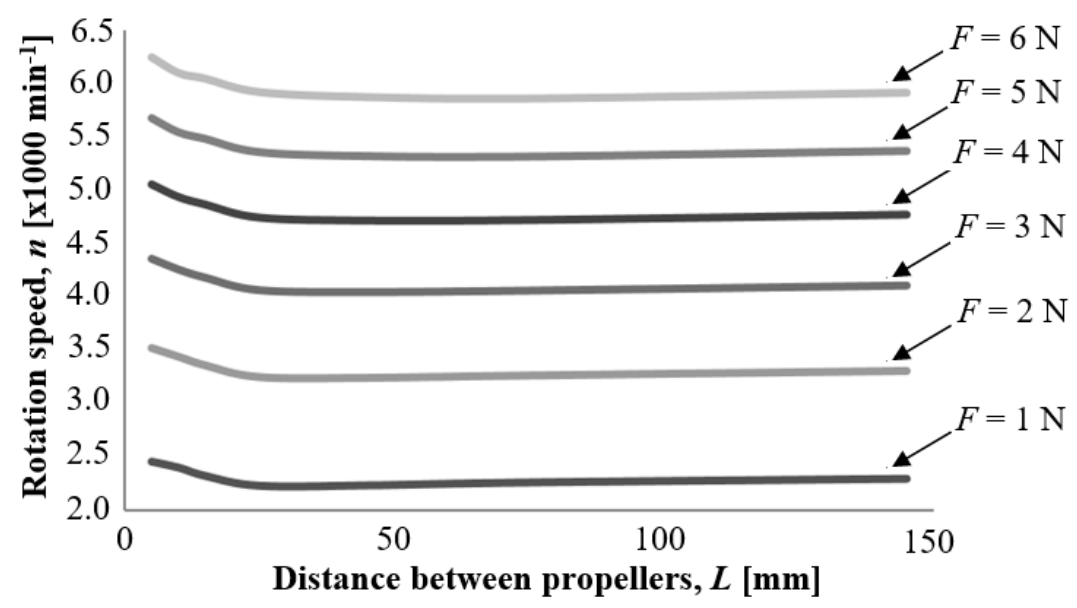

Figure 15. Dependency of the propeller rotation speed on the distance between the propellers. The propeller is producing a definite lifting force.

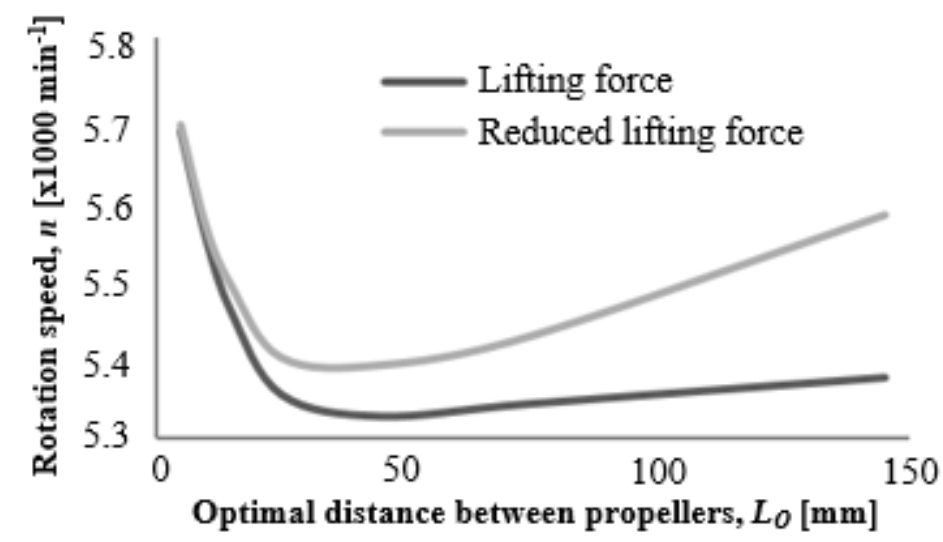

Figure 16. Optimal distance between $254 \mathrm{~mm}$ propellers at producing of $5 \mathrm{~N}$ force.

From Figure 16 it can be seen that the $254 \mathrm{~mm}$ quadcopters have different optimal distances between the propellers at different rotation speeds to generate the same force. The same data obtained from non-linear regression was used (Figure 15) to find optimal distances that corresponded to different lifting forces (Figure 17). Distance dependency on the lifting force for $254 \mathrm{~mm}$ propellers can be calculated by Eq. (5)

$$
L_{O-10}=0.55 F_{1}^{2}-0.24 F_{1}+29.75 \text {. }
$$

To create the calculation method of optimal gap distance, CFD simulations, in addition to the propeller $254 \times 127 \mathrm{~mm}$, were done for propellers $203.2 \times 101.6 \mathrm{~mm}$ and $304.8 \mathrm{x}$ $152.4 \mathrm{~mm}$. The calculations were done on different distances between propellers and different angular velocities with the same parameters that were used for $254 \mathrm{~mm}$ propeller calculations. Figure 18 shows the comparison between the lifting forces produced by three different propellers at the angular velocity of $5000 \mathrm{~min}^{-1}$. 
Dependencies of optimal distances on the propeller diameter for different lifting forces are presented in Figure 19. It can be seen that these dependencies can be represented by similar laws for forces $2 \mathrm{~N}, 4 \mathrm{~N}$, and $6 \mathrm{~N}$. Common dependency can be described by Eq. 6

$$
L_{d}=0.15 \cdot D-38.10
$$

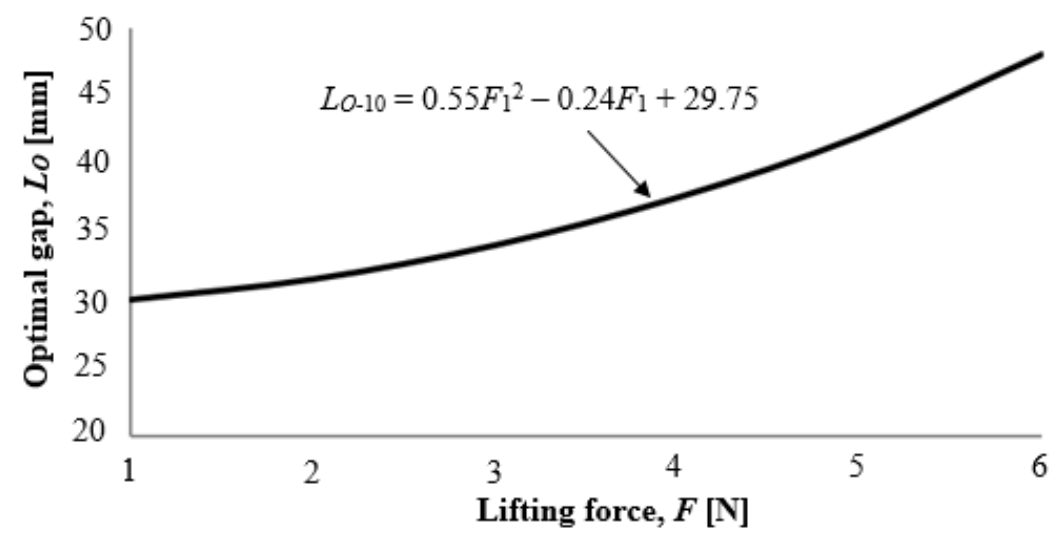

Figure 17. Optimal distances between $254 \mathrm{~mm}$ propellers for different lifting forces.

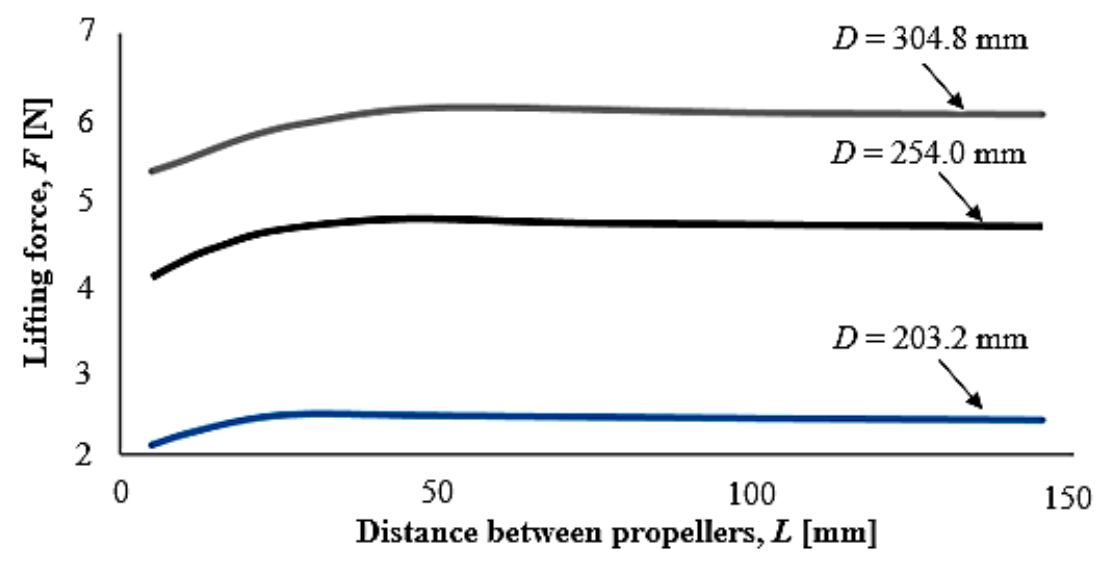

Figure 18. Lifting force produced by the propeller with the rotation speed of $5000 \mathrm{~min}^{-1}$.

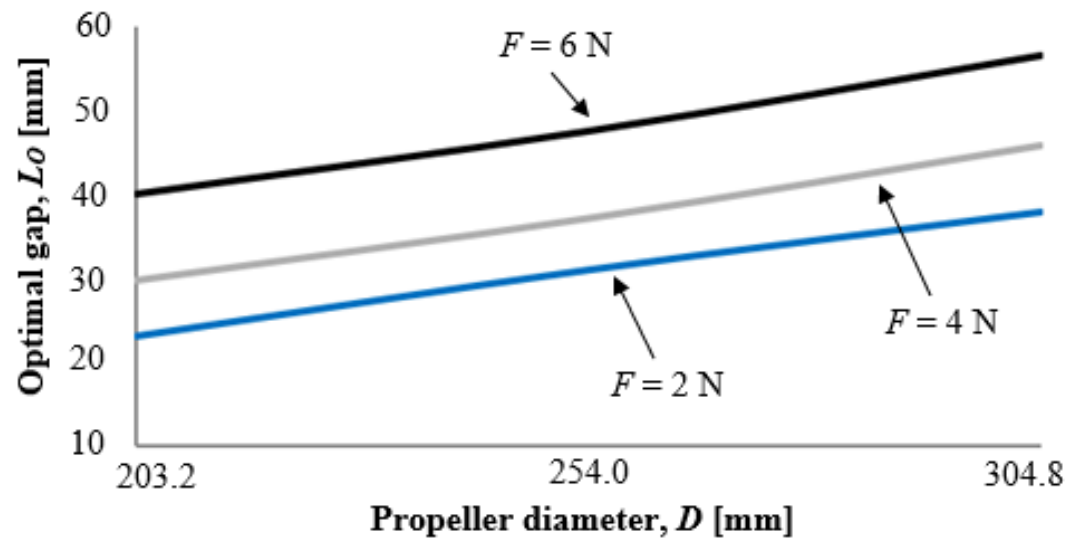

Figure 19. Optimal distances between propellers with different diameters (for generating force of $2 \mathrm{~N}, 4 \mathrm{~N}$, and $6 \mathrm{~N}$ ). 
After substitutions in Eq. 5 and 6, Eq. 7 can be obtained. With this formula, it is possible to find an optimal distance between the propellers for a quadcopter with propeller pitch equal to half of the diameter at a defined lifting force. The calculation results are shown in Figure 20.

$$
L=0.55 \cdot F^{2}-0.24 \cdot F+0.15 \cdot D-8.35
$$

To ensure that Eq. 7 was applicable to a larger amount of propellers (not only for cases where the rotor's pitch was equal to the radius), force correction should be added and the results can be presented as an equation pair (Eq. 8)

$$
\left\{\begin{array}{l}
F_{C}=\left(P-\frac{D}{2}\right) \cdot\left(3.27 \cdot 10^{-4} \cdot D-4.72 \cdot 10^{-2}\right) \\
L=0.55 \cdot\left(F+F_{c}\right)^{2}-0.24 \cdot\left(F+F_{c}\right)+0.15 \cdot D-8.35
\end{array} .\right.
$$

The coefficient of determination gave a very precise result. Changing the optimal distance by $\pm 8 \%$, power consumption will change slightly, around $1 \%$. Equation 8 can be used within the propeller's diameter range $177.8 \mathrm{~mm}-355.6 \mathrm{~mm}$ in which the pitch was equal to $0.3-0.7$ of the propeller diameter. Propeller's rotation speed must be within $2000 \mathrm{~min}^{-1}-8000 \mathrm{~min}^{-1}$.

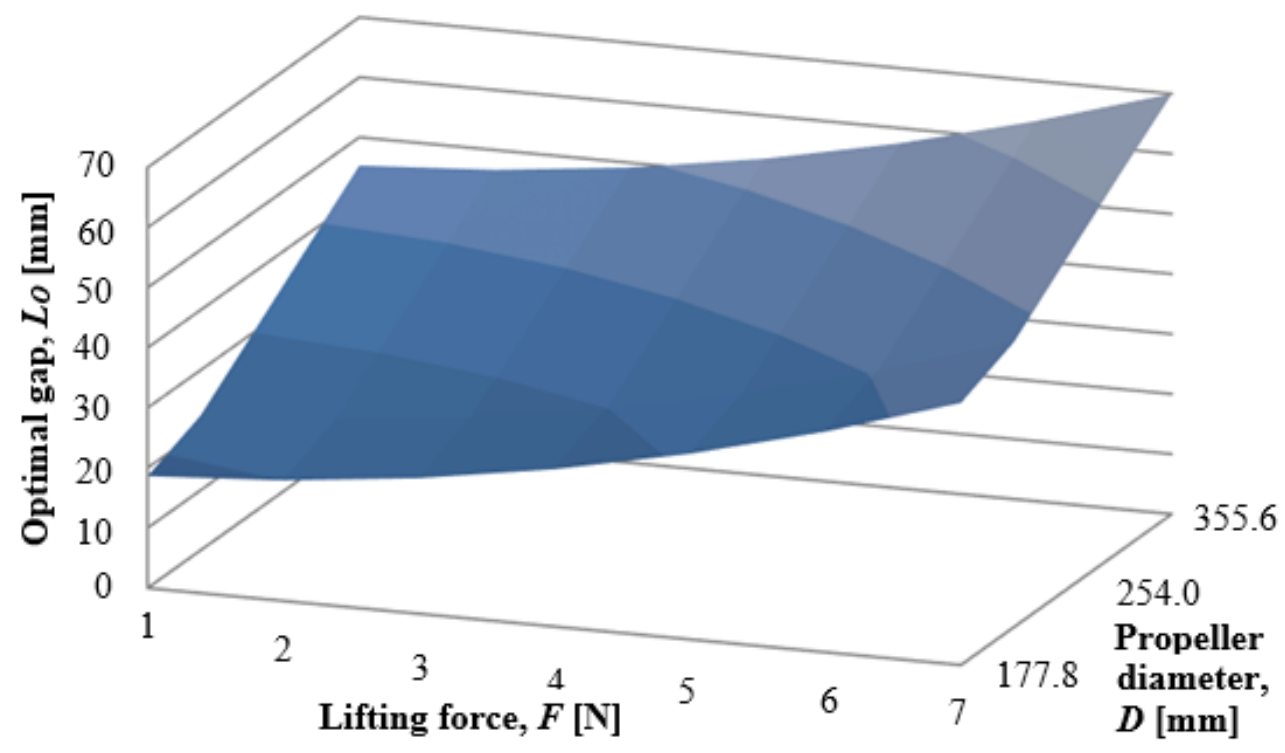

Figure 20. Optimal distances between the propellers.

To simplify the use of Eq. (8), widely used propeller sizes and masses of quadrotor helicopters were considered and the calculation results are presented in Table 1. The table contains optimal distances between propellers for different quadrotors, propeller pitches, and helicopter masses. Theoretically, the equation pair (Eq. 8) can be used not only for quadrotor helicopters but also for multicopters with $3,6,8$, and other numbers of rotors. 
Table 1. Optimal distance between axis of propellers, (mm).

\begin{tabular}{ccccccccccc}
\hline $\begin{array}{c}\text { Diameter } \\
\text { [in] }\end{array}$ & $\begin{array}{c}\text { Pitch } \\
\text { [in] }\end{array}$ & 1000 & 1250 & 1500 & 1750 & 2000 & 2250 & 2500 & 2750 & 3000 \\
\hline 7 & 3.5 & 199 & 201 & 203 & 206 & 209 & 212 & 216 & 220 & 225 \\
7 & 4.0 & 199 & 201 & 204 & 206 & 209 & 213 & 217 & 221 & 226 \\
7 & 4.5 & 200 & 202 & 204 & 207 & 210 & 214 & 218 & 223 & 228 \\
8 & 4.0 & 228 & 230 & 232 & 235 & 238 & 241 & 245 & 250 & 254 \\
8 & 7.5 & 234 & 237 & 240 & 244 & 248 & 253 & 258 & 264 & 270 \\
9 & 4.5 & 257 & 259 & 261 & 264 & 267 & 271 & 275 & 279 & 284 \\
9 & 6.0 & 261 & 263 & 266 & 269 & 273 & 277 & 282 & 287 & 293 \\
10 & 3.7 & 284 & 285 & 287 & 289 & 291 & 294 & 297 & 300 & 304 \\
10 & 4.7 & 286 & 288 & 290 & 292 & 295 & 298 & 302 & 306 & 311 \\
10 & 5.0 & 287 & 288 & 291 & 293 & 296 & 300 & 304 & 308 & 313 \\
10 & 6.0 & 289 & 292 & 295 & 298 & 302 & 306 & 310 & 315 & 321 \\
11 & 5.5 & 316 & 318 & 320 & 322 & 326 & 329 & 333 & 337 & 342 \\
11 & 6.5 & 319 & 322 & 325 & 328 & 332 & 336 & 341 & 346 & 352 \\
12 & 4.5 & 342 & 343 & 343 & 345 & 346 & 349 & 351 & 354 & 357 \\
12 & 6.0 & 345 & 347 & 349 & 352 & 355 & 358 & 362 & 367 & 371 \\
12 & 7.0 & 349 & 352 & 355 & 359 & 363 & 367 & 372 & 377 & 383 \\
14 & 6.0 & 401 & 401 & 402 & 404 & 406 & 408 & 411 & 414 & 417 \\
14 & 7.0 & 403 & 405 & 407 & 410 & 413 & 417 & 421 & 425 & 430 \\
14 & 8.0 & 410 & 413 & 416 & 420 & 424 & 429 & 434 & 439 & 445 \\
\hline
\end{tabular}

\section{CONCLUSIONS}

Lifting force of a quadcopter depends on different geometrical parameters. Normally, lifting force will increase with the increasing of propeller pitch. For different rotation velocities, this increasing is different but in all cases it can be approximated by a linear relationship. To obtain dependency functions, CFD simulations and laboratory experiments were carried out and an equation for calculation of lifting force, taking into account the pitch influence, was derived. Results showed a linear relationship between propeller pitch and the produced lifting force and proposed calculation equation gave reliable results at pitch values equal to $0.3-0.7$ of the propeller diameter and at rotation velocities $2000 \mathrm{~min}^{-1}-8000 \mathrm{~min}^{-1}$. Analysis of mini quadcopter efficiency was carried out, taking into account the vehicle mass and lifting force produced by all propellers. CFD simulations showed that the lifting force of a quadcopter increased about $15 \%$ on the distances between propellers from $5 \mathrm{~mm}$ to $35 \mathrm{~mm}$. From a distance of $70 \mathrm{~mm}$, the lifting force will decrease about $2 \%$ and then will stabilise. Laboratory tests gave practically the same results. Deviation was about 3\%. At increasing of distance between propellers from $5 \mathrm{~mm}$ until $25 \mathrm{~mm}$, the power consumption decreased $8 \%-10 \%$ and after the gap distance equal to $40 \mathrm{~mm}$, it will be stable and minimal. Based on the experimental tests and analyses, one can assert that quadcopters have different optimal distances between the propellers at different rotation speeds to generate the same force. Equations for calculation of optimal gap distances for different multicopters were derived and calculation results were presented in graphs and tables. For example, for a quadcopter with propeller $254 \mathrm{~mm} \times 127 \mathrm{~mm}$ and total mass of UAV equal to $1 \mathrm{~kg}$, the optimal gap between propellers would be $33 \mathrm{~mm}$. If the mass of the same design of UAV is equal to $2.5 \mathrm{~kg}$, then the optimal gap would be $50 \mathrm{~mm}$. 


\section{ACKNOWLEDGEMENTS}

This research work was supported by innovative Manufacturing Engineering Systems Competence Centre IMECC (supported by Enterprise Estonia and co-financed by the European Union Regional Development Fund, project EU48685); Estonian Research Council grant PUT1300; the Estonian Centre of Excellence in Zero Energy and Resource Efficient Smart Buildings and Districts, ZEBE, grant TK146 funded by the European Regional Development Fund.

\section{REFERENCES}

[1] Coifman B, McCord M, Mishalani RG, Iswalt M, Ji Y. Roadway traffic monitoring from an unmanned aerial vehicle. IEE Proceedings-Intelligent Transport Systems: IET; 2006. p. 11-20.

[2] Casbeer DW, Kingston DB, Beard RW, McLain TW. Cooperative forest fire surveillance using a team of small unmanned air vehicles. International Journal of Systems Science. 2006;37:351-60.

[3] Xiaofeng L, Zhongren P, Zhang L, Li L. Unmanned aerial vehicle route planning for traffic information collection. Journal of Transportation Systems Engineering and Information Technology. 2012;12:91-7.

[4] Jerry M. Current and Future UAV Military Users and Applications. Air\& Space Europe. 1999;1:51-8.

[5] Mejias L, Saripalli S, Campoy P, Sukhatme GS. Visual servoing of an autonomous helicopter in urban areas using feature tracking. Journal of Field Robotics. 2006;23:185-99.

[6] Poyi GT, Wu MH, Bousbaine A, Wiggins B. Validation of a quad-rotor helicopter matlab/simulink and solidworks models. 2013.

[7] Bousbaine A, Wu MH, Poyi GT. Modelling and simulation of a quad-rotor helicopter. 2012.

[8] Wisniewski C, Byerley A, Van Treuren KW, Hays A. A Comparison of the Aerodynamic Performance and Aeroacoustic Behavior of Commercial and Custom Designed Quadcopter Propellers. 55th AIAA Aerospace Sciences Meeting2017. p. 1173.

[9] Roldán JJ, Joossen G, Sanz D, del Cerro J, Barrientos A. Mini-UAV based sensory system for measuring environmental variables in greenhouses. Sensors. 2015;15:3334-50.

[10] Xiang H, Tian L. Development of a low-cost agricultural remote sensing system based on an autonomous unmanned aerial vehicle (UAV). Biosystems Engineering. 2011;108:174-90.

[11] Feng L, Ben MC, Yew LK. Integration and Implementation of a Low-cost and Vision-based UAV Tracking System. Control Conference, 2007 CCC 2007 Chinese: IEEE; 2007. p. 731-6.

[12] Sharp CS, Shakernia O, Sastry SS. A vision system for landing an unmanned aerial vehicle. Robotics and Automation, 2001 Proceedings 2001 ICRA IEEE International Conference on: Ieee; 2001. p. 1720-7.

[13] Girard AR, Howell AS, Hedrick JK. Border patrol and surveillance missions using multiple unmanned air vehicles. Decision and Control, 2004 CDC 43rd IEEE Conference on: IEEE; 2004. p. 620-5. 
[14] Peng K, Cai G, Chen BM, Dong M, Lum KY, Lee TH. Design and implementation of an autonomous flight control law for a UAV helicopter. Automatica. 2009;45:2333-8.

[15] Walendziuk W, Oldziej D, Golinski P. A laboratory stand for research concerning drive units applied in unmanned flying micro vehicles. Photonics Applications in Astronomy, Communications, Industry, and High-Energy Physics Experiments 2015: International Society for Optics and Photonics; 2015. p. 966214.

[16] Ołdziej D, Gosiewski Z. Modelling of dynamic and control of six-rotor autonomous unmanned aerial vehicle. Solid State Phenomena: Trans Tech Publ; 2013. p. 220-5.

[17] Hassanalian M, Abdelkefi A. Design, manufacturing, and flight testing of a fixed wing micro air vehicle with Zimmerman planform. Meccanica. 2017;52:1265-82.

[18] KAMBUSHEV M, BILIDEROV S, VARBANOV Y. Synthesis And Study Of The Mathematical Model Of A Tricopter. International Scientific Committee. 2016:149.

[19] Paw YC, Balas GJ. Development and application of an integrated framework for small UAV flight control development. Mechatronics. 2011;21:789-802.

[20] Shim DH, Kim HJ, Sastry S. Control system design for rotorcraft-based unmanned aerial vehicles using time-domain system identification. Control Applications, 2000 Proceedings of the 2000 IEEE International Conference on: IEEE; 2000. p. 808-13.

[21] Johnson EN, Kannan SK. Adaptive trajectory control for autonomous helicopters. Journal of Guidance, Control, and Dynamics. 2005;28:524-38.

[22] Kambushev M. BS. Determination of aerodynamic coefficients necessary for the control of MAVs. TransMotauto World. 2017;2:94-7.

[23] Yoon J, Lee J. Approximate Multi-Objective Optimization of a Quadcopter Through Proportional-Integral-Derivative Control. Transactions of the Korean Society of Mechanical Engineers A. 2015;39:673-9.

[24] Sumantri B, Uchiyama N, Sano S. Least square based sliding mode control for a quad-rotor helicopter and energy saving by chattering reduction. Mechanical Systems and Signal Processing. 2016;66:769-84.

[25] Kendoul F. Survey of advances in guidance, navigation, and control of unmanned rotorcraft systems. Journal of Field Robotics. 2012;29:315-78.

[26] Zhang W, Fan N, Wang Z, Wu Y. Modeling and aerodynamic analysis of a ducted-fan micro aerial vehicle. Modelling, Identification \& Control (ICMIC), 2012 Proceedings of International Conference on: IEEE; 2012. p. 768-73.

[27] E. JN. Theory of Elasticity, Railways, Automobiles. Collected Papers. 1937;III:48-56.

[28] Velikanov N, Koryagin S, Sharkov O. Definition of Locked-up Stresses around a Rectilinear Welding Seam. IOP Conference Series: Materials Science and Engineering: IOP Publishing; 2016. p. 012094.

[29] Sharkov O, Kalinin A. Kinematic characteristics of pulsed speed regulators. Russian Engineering Research. 2009;29:551-4.

[30] Eleftherios A, Tsili MA, Spathopoulos V, Hatziefremidis A. Energy Efficiency Optimization in UAVs. Materials Science Forum2014. p. 281-6.

[31] Wisniewski CF, Byerley AR, Heiser W, Van Treuren KW, Liller T. Designing Small Propellers for Optimum Efficiency and Low Noise Footprint. 33rd AIAA Applied Aerodynamics conference2015. p. 2267. 
[32] Wisniewski CF, Byerley AR, Heiser W, Van Treuren KW, Liller T. The Influence of Airfoil Shape, Reynolds Number and Chord Length on Small Propeller Performance and Noise. 33rd AIAA Applied Aerodynamics Conference2015. p. 2266.

[33] Ramasamy D, Yuan GC, Bakar RA, Zainal Z. Validation Of Road Load Characteristic Of A Sub-Compact Vehicle By Engine Operation. International Journal of Automotive \& Mechanical Engineering. 2014;9.

[34] Otsuka H, Nagatani K. Thrust loss saving design of overlapping rotor arrangement on small multirotor unmanned aerial vehicles. Robotics and Automation (ICRA), 2016 IEEE International Conference on: IEEE; 2016. p. 3242-8.

[35] Aleksandrov D, Penkov I. Optimization of Lift Force of Mini Quadrotor Helicopter by Changing of Gap Size Between Rotors. Solid State Phenomena: Trans Tech Publ; 2013. p. 226-31.

[36] Sakinah MH, Amirruddin AK, Kadirgama K, Ramasamy D, Rahman MM, Noor MM. The application of response surface methodology in the investigation of the tribological behavior of palm cooking oil blended in engine oil. Advances in Tribology. 2016;2016.

[37] Najiha M, Rahman M, Kadirgama K, Noor M, Ramasamy D. Multi-objective optimization of minimum quantity lubrication in end milling of aluminum alloy AA6061T6. International Journal of Automotive and Mechanical Engineering. 2015;12:3003.

\section{NOMENCLATURE}

UAV - Unmanned Aerial Vehicle,

CFD - Computational Fluid Dynamics,

FVM - Finite Volume Method,

$D$ - propeller diameter, $\mathrm{N}$,

$F-\quad$ lifting force, N,

$F_{1}-\quad$ required one propeller lifting force for holding helicopter in hover, N,

$F_{C}-$ overall coefficient of the correction of lifting force, N,

$F_{C-8}-$ correction coefficient of lifting force for $203.2 \mathrm{~mm}$ propeller, N,

$F_{C-10}$ - correction coefficient of lifting force for $254 \mathrm{~mm}$ propeller, N,

$F_{C-12}-$ correction coefficient of lifting force for $304.8 \mathrm{~mm}$ propeller, $\mathrm{N}$,

$L-\quad$ gap distance between propellers, $\mathrm{mm}$,

$L_{O}-\quad$ optimal gap distance between propellers, $\mathrm{mm}$,

$L_{O-10}$ - optimal gap distance between $254 \mathrm{~mm}$ propellers, $\mathrm{mm}$,

$L_{d}-\quad$ optimal gap distance on the propeller diameter, $\mathrm{mm}$,

$N-$ power, W,

$P$ - propeller pitch, $\mathrm{mm}$,

$R-\quad$ propeller radius, $\mathrm{mm}$,

$n-\quad$ rotation speed, $\min ^{-1}$,

$\alpha-\quad$ angle between the propeller cord and the horizontal plane, deg. 